\title{
Design of Adaptive LED Supplemental Lighting System Based on LabVIEW
}

\author{
Pingjuan Niu ${ }^{1,2 *}$, Yanyan $\mathrm{Li}^{1,2}$, Huijuan Tian ${ }^{1,2}$ and Zhengxiao $\mathrm{Su}^{2}$ \\ ${ }^{1}$ School of Electrical Engineering and Automation, Tianjin Polytechnic University, \\ China \\ ${ }^{2}$ Engineering Research Center of High Power Solid State Lighting Application \\ System, China \\ NPing_tjpu@163.com
}

\begin{abstract}
With the global increase in energy prices and the urgent need to reduce $\mathrm{CO}_{2}$ emissions to the atmosphere, high energy usage is the main problem the greenhouse indust y facing. Optimized control of supplemental lighting intensity and quality help to improve productivity and energy efficiency of greenhouse.In this paper, $L$ ED light source module is developed according to the design of light distribution of RRGB chip based on plants need for uniform lighting. Adaptive LED supplementary lighting sustem realize collection, storage and call of environmental data, and adaptive regulation of red, green, and blue light output based on combination of uppen computer LabVIEW and controller STM32.PC based on LabVIEW monitor environmental parameters, and call or choose PPFD setting value of red, green, blue three bands of light based on expert database. The controller communicating with LabVIEW wirlessty through WiFi module, conducts real-time detection and adaptive regulation on photosynthetic photon flux density (PPFD) of red, green and blue bands according to PPFD setting value. This intelligent supplemental lighting system meets the requirement of plants for lighting environment and greatly saving energies through adaptive adjustment of PPFD of red, green and blue bands in environment according to the setting based on different supplemental lighting demands of differen plants or the same plant in different growth stages for PPFD and light quality ratio.
\end{abstract}

Keyword : LED supptement lighting, LabVIEW, PWM, PPFD, light quality ratio

\section{Introduction}

Artificial lighting is especially important for the growth of greenhouse plants in the environmenf with increasingly severe haze. Light intensity and light quality play an importan role in the photosynthesis, material metabolism and morphogenesis of plants [1]. $380-780 \mathrm{~nm}$ visible spectrum band is the optical band mainly absorbed by the photosynthesis of plants. Absorption peak occurs in red and blue optical bands [2] and the addition of a certain proportion of green light can promote the growth of plants [3, 4]. As a new light source applied to plant lighting, LED has advantages such as strong reliability, long life, small volume, less heat and low energy consumption compared to traditional light source. As it can emit single wavelength light, accurate configuration of spectrum can be realized according to the requirement of plants [5]. One super-bright LED alone cannot provide adequate light for the normal growth of greenhouse plants, but multiple LEDs can meet the fill lighting demand of plants through modular configuration design [6-9]. Traditional supplemental lighting generally keep definite light intensity and quality [10-12] and the light exposure to plants change with the change of ambient light, which cannot meet different demands of different plants or the same plant in different growth 
stages for PPFD and light quality ratio [1,13,14].Meanwhile, it wastes energies and increases costs. The adaptive LED supplemental lighting system in this paper designs LED light source modules of red, green and blue bands with uniform distribution of irradiance, conducts real-time monitoring and sets ambient light intensity, temperature and humidity through upper computer. The controller adjusts PWM signal dynamically according to the change of light intensity so as to control output of LED red, green and blue light source modules and maintain the given PPFD and light quality proportion accurately, which reduces costs and meets the demand of plants.

\section{LED Light Source Module}

Small-power chip have more uniform mixing of PPFD of different spectrums compared with high-power chip and it is used to illuminate plants in a near distance. This paper select $0.2 \mathrm{~W}$ paster-type RRGB lamp head for design of LED light source. Figure 1 shows the relational graph of $\mathrm{R}, \mathrm{G}$ and $\mathrm{B}$ light quantum and electric current in single RRGB lamp head measured with measurement system composed of HAAS-2000 high-precision rapid spectral radiometer and small integrating sphere procuced by Hangzhou Everfine Photoelectricity Company.

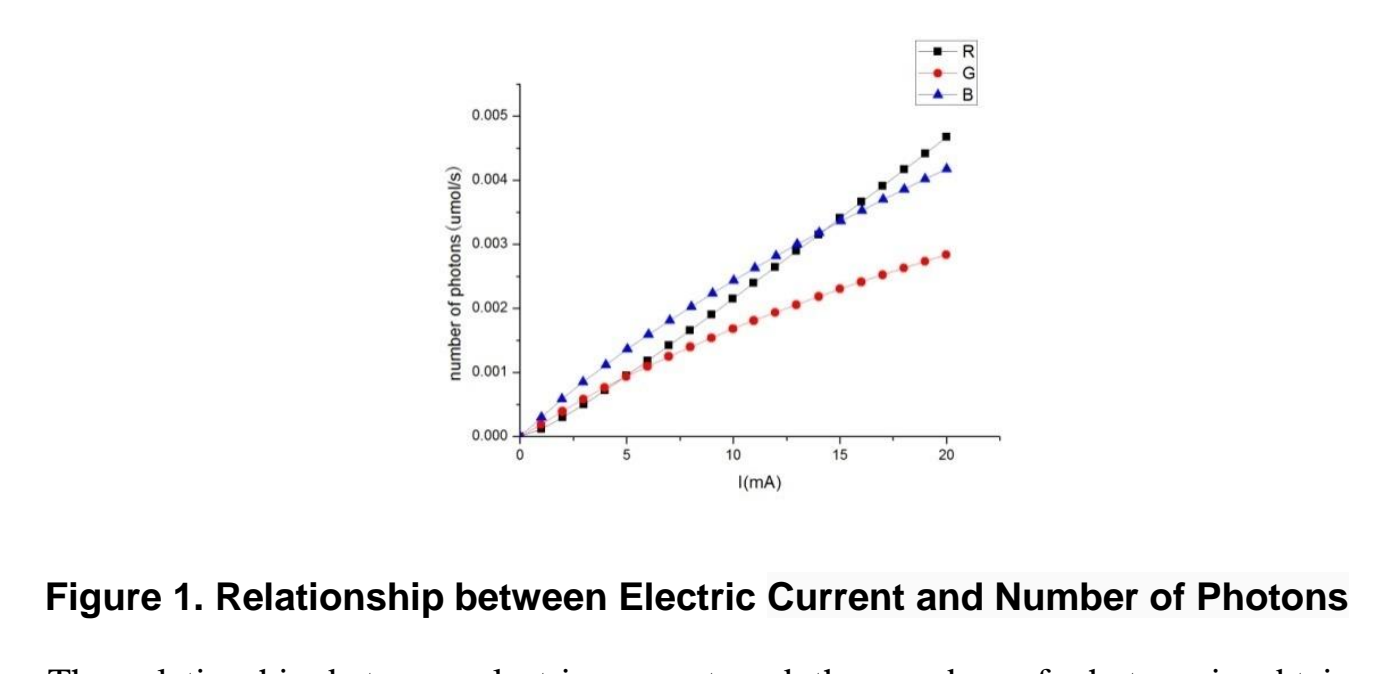

The relationship between electric current and the number of photons is obtained through linear filting of data?

$$
\begin{gathered}
\mathrm{y}_{\mathrm{R}}=0.0002 \mathrm{x}_{\mathrm{R}} \quad, \mathrm{R}^{2}=0.9925 \\
\mathrm{y}_{\mathrm{B}}=0.0002 \mathrm{x}_{\mathrm{B}} \quad, \mathrm{R}^{2}=0.9754 \\
\mathrm{y}_{\mathrm{G}}=0.0002 \mathrm{x}_{\mathrm{G}} \quad, \mathrm{R}^{2}=0.9714
\end{gathered}
$$

Where, $y_{R}, y_{B}$ and $y_{G}$ refer to the number of red, blue and green photons and $x_{R}, x_{B}$ and $\mathrm{x}_{\mathrm{G}}$ refer to the eurrent of red, blue and green chips. The goodness of fit $\mathrm{R}^{2}$ is close to 1 . Therefore, the current and the number of photons of red, green and blue LED light sour es basically have relationship of positive and linear proportion.

In reference [4], when planted under lighting conditions of $70 \%$ red light, $20 \%$ green light and $10 \%$ blue light,both lettuce and radicchio plants grown at $220 \mu \mathrm{mol} \cdot \mathrm{m}^{-2} \cdot \mathrm{s}^{-1}$ Photosynthetic Photon Flux Density (PPFD) express higher photochemical activity of Photosystem II (PSII) than $400 \mu \mathrm{mol} \cdot \mathrm{m}^{-2} \cdot \mathrm{s}^{-1}$ PPFD grown plants, evaluated by effective quantum yield of Photosystem II $\left(\Phi_{\mathrm{PSII}}\right)$. Therefore, when light quality ratio is $\mathrm{R}: \mathrm{B}: \mathrm{G}=7: 1: 2$, the current of single lamp head $\mathrm{R}, \mathrm{R}, \mathrm{G}$ and $\mathrm{B}$ is respectively $20 \mathrm{~mA}, 20 \mathrm{~mA}$, $16 \mathrm{~mA}$ and $6 \mathrm{~mA}$ during simulation, which is specified according to proportional relationship between number of photons and current of light sources.

Plant lighting is different from ordinary lighting. Currently, there are two common basic measuring methods for evaluating plant illumination effect, namely photosynthetically active radiation energy (PAR) method and photosynthetic photon flux 
method. In PAR method, irradiance as physical quantity represent the radiant power number promoting photosynthesis per square meter and then represent the degree of illumination of plants. Photosynthetic photon flux method uses the number of photons exposured every second per unit area [7,15].Irradiance is used to represent illumination degree in the simulation of optical software TracePro and PPFD value is used to refer to plant illumination in actual greenhouse environment. They can realize transition.

81 lamp heads are arranged into a square light source module with 9 rows and 9 columns. Based on theoretical research foundation, TracePro respectively simulates the irradiance when the LED spacing $\mathrm{L}$ is $7.5 \mathrm{~mm}, 10 \mathrm{~cm}, 12.5 \mathrm{~mm}$ and $15 \mathrm{~mm}$. The height from illumination plane to LED light module is $20 \mathrm{~cm}$.

The computational formula $[8,9]$ of illumination area of LED light source unit module on the reference plane of illumination is as below:

$$
\mathrm{S}=\left[7 \mathrm{~L}+2 \mathrm{~h} \tan \left(\frac{13.2 \pi}{180}\right)\right]^{2}
$$

$\mathrm{L}$ is the distance between two light sources and $\mathrm{h}$ is the distance between lamp panel and illumination plane. So irradiation area $\mathrm{S}$ is respectively $146^{2} \mathrm{~mm}^{2} 、 164^{2} \mathrm{~mm}^{2}, 180^{2}$ $\mathrm{mm}^{2}$ 和 $200^{2} \mathrm{~mm}^{2}$.

LED light source module simulation model is established with TracePro. Irradiance analysis diagram under different LED spacing is achieved by tracing ray of selected LED light source ,as shown in Figure 2.

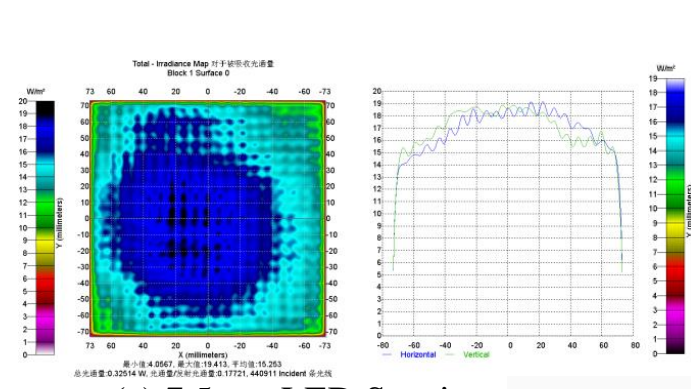

(a) $7.5 \mathrm{~mm}$ LED Spacing

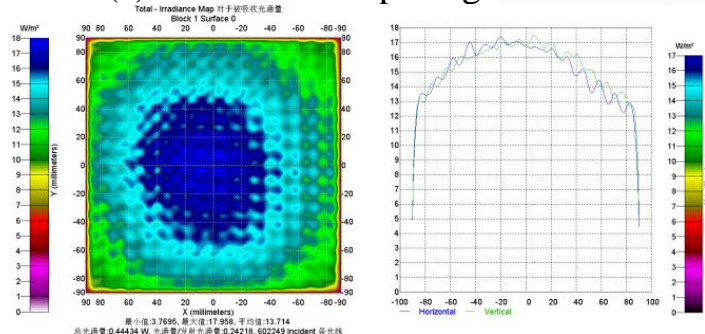

(c) $125 \mathrm{mmLED}$ Spacing

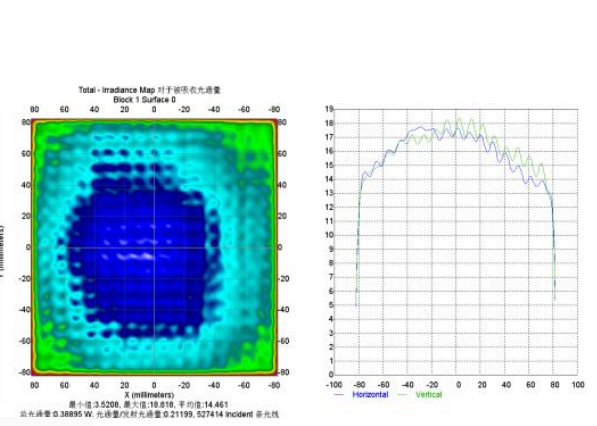

(b) $10 \mathrm{~mm}$ LED Spacing

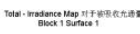

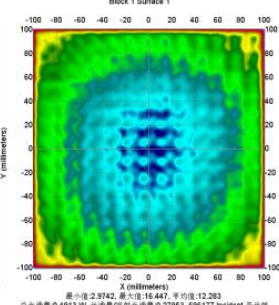

(d) $15 \mathrm{~mm}$ LED Spacing

Figure 2. Irradiance Map Simulated by TracePro with Different LED Spacing.

It car be seen that illumination distribution of irradiance intensity is the biggest in the center position, and gradually reduce from center to both sides, especially sharply decline on the edge. Irradiance map showed that distribution of irradiance with $15 \mathrm{~mm}$ LED spaeing is most symmetrical. Distribution curve of horizontal direction is basically coincidence with vertical direction, and the uniformity of irradiance is best.So light source interval is $1.5 \mathrm{~cm}$, which is selected on the basis of meeting irradiance density, because it has not only high uniformity, but also wide irradiation area.

\section{System Hardware Design}

The system uses modular design, including detection module, control module, driving power module, WiFi module,LED light source module and LabVIEW upper computer module. Figure 3 shows the schematic diagram of the system. 


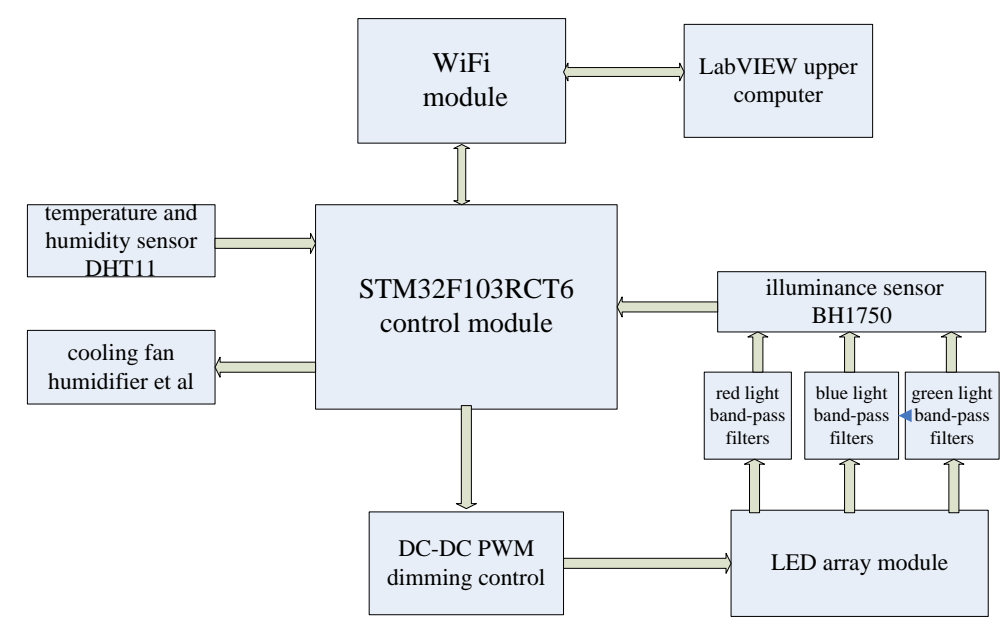

Figure 3. The Block Diagram of System

\subsection{Detection Module}

The detection module conducts real-time detection on red, green and blue light illuminance, temperature and humidity values in the environment transmits the detection signal to microcomputer and completes data acquisition. When LED light sources are all alight, red, green and blue wavelength bands exist simultaneously in the environment. To detect red, green and blue light intensities respectively, illumination is first preprocessed by blue, green and red light band-pass filters with a light transmittance of $90 \%$ and wavelength scope respectively of $420-480 \mathrm{~nm}, 500-580 \mathrm{~nm}$ and $625-700 \mathrm{~nm}[16,17]$. Processed red, green and blue lights are detected by photosensitive diode of illumination sensor BH1750FVI. Optical signalis transformed into digital signal and transmitted to P2 port of microcomputer. Similarly, temperature and humidity sensor DHT11 transforms temperature and humidity into digital signal, thus realizing the detection of temperature and humidity. Figure 4 is the circuit diagram of detection module.

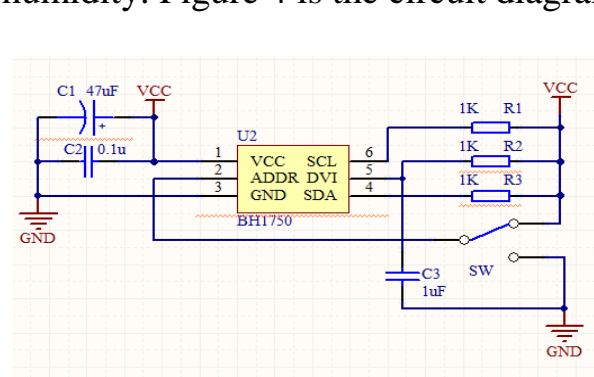

(a)

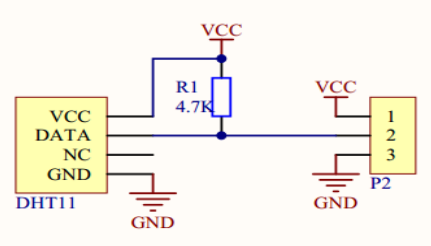

(b)

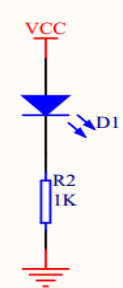

Figure 4. Circuit Diagram of Detection Module

(b) Temperature and Humidity Sensor DHT11

\subsection{Control Module}

The system uses microcomputer STM32F103RCT6 as controller with output waveform frequency $9600 \mathrm{~Hz}$. For the connection with the detection part, temperature and humidity sensor DHT11 is connected through P1.1 port; illumination sensor is connected through P2 port; IIC clock pin SCL of illumination sensor is connected through P2.1, P2.3 and P2.5; IIC data pin SDA is connected through P2.2, P2.4 and P2.6. Microcomputer realizes PWM signal output through software programming. It outputs three PWM signals to power driving module through P0.0, P0.1 and P0.2 and adaptively adjusts PPFD of red, 
green and blue LED light sources.Microcomputer communicates with upper computer wirelessly through $\mathrm{WiFi}$ module. A power source with voltage $5 \mathrm{~V}$ and $3.3 \mathrm{~V}$ supplies power for it.

\subsection{Power Driving Module}

This system uses DC-DC boost LED lighting module designed based on DHC018SXO boost-type DC power converter chip. PWM signal with variable pulse width is loaded on PWM lighting input pin of DHC018SXO chip. The light intensity of LED is adjusted through the adjustment of driving current of LED. Figure 5 shows the changing curve of output current of R, G and B LED driving power under the regulation of PWM lighting signal. When duty ratio is $100 \%$, driving output current is the rated current of LED light source module. R, G and B rated currents are respectively $360 \mathrm{~mA}, 180 \mathrm{~mA}$ and $180 \mathrm{~mA}$, and changing curve of green light source basically coincides with that of blue light. According to the Figure, duty cycle and output current have positive and nonlinear proportion relationship and formula $\mathrm{I}=\mathrm{D} \mathrm{I}_{\max }[18]$ is not appropriate to this driving power. Therefore, the adjustment of supplemental lighting amount through the proportional relation of PWM and LED output quantity is not appropriate to this system. So we propose control method of constant feedback and adjustmentto PWM duty gycle so as to adjust the drive current to achieve the set illuminance alue of R,G,B wavelength bands adaptively .

\section{Figure 5. Relation Curve between LED Drive Current and PWM Duty Cycle}

\subsection{Wifi Module}

Using WiFi module, system makes up for the complex connection of serial circuit and the communication inconvenience subject to limit of lines, realizing wireless communication between lighting control terminal and PC monitoring. System select embeddea UART- TLN13UA06 WiFi module, which is based on UART interface and up to WiFi standard. Built-in IEEE802.11 wireless networking protocol stack and TCP/IP protocol stack, UART-TLN13UA06 WiFi module can realize conversion from serial data to wireless network.It can realize wireless transmission of data easily without making any changes to the original serial port devices if connection line of serial port is replaced by WiFi module on the basic of original serial port devices. Connection diagram between TLN13UA06 WiFi module and external hardware is showed in Figure 6. Module power supply is voltage of $3.3 \mathrm{~V}$, which is standard TTL power supply. Pin $1 \sim 4$ have optional features, and pin $5 \sim 8$ is used for serial port communication. Two LED indicator lights of red and green is used to indicate the state of power and network. 


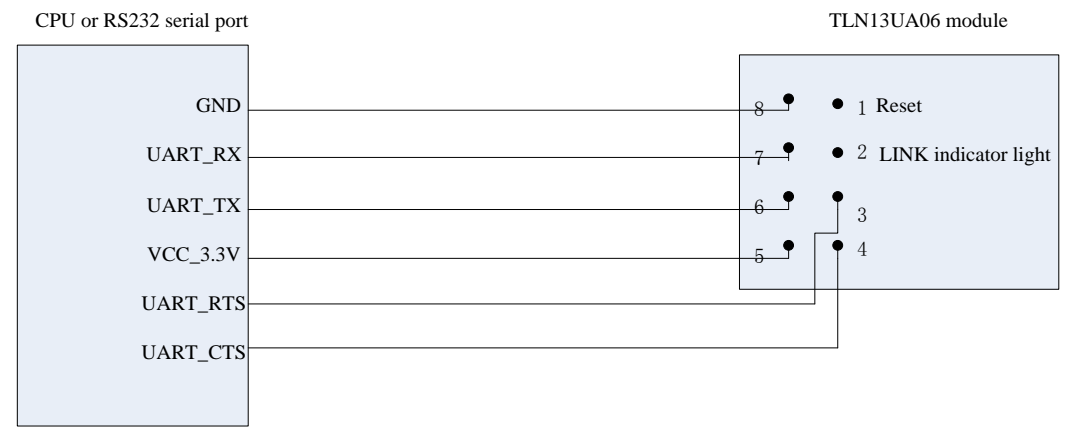

\section{Figure 6. TLN13UA06 WiFi Module Connection Diagram with External Hardware}

\section{Software Design of System}

System software design mainly includes the software design of upper computer interface and lower computer control. LabVIEW realizes oftware design of upper computer interface with graphics language (G language). Upper computer interface sets PPFD value of R, G, B light and upper and lower limits of temperature \& humidity plants required. Controller realize adaptive regulation according to setting PPFD value of R,G,B wavelength band.

\subsection{Software Design of Controller}

Figure 7 shows the software flow char of control part of system. After the startup of controller, the system is first intialized, including the initialization of serial port, temperature \&humidity senso, illuminance sensors and timer. Then, controller communicate with detection module When the communication is successful, ambient temperature \& humidity and illuminance value are sent to WiFi module by serial port, then transmit to PC wirelessly through WiFi module. PC as server sets appropriate PPFD value of $R, G, B$ band light which convert into illuminance. Controller compare illuminance value of $R, G, B$ light in environment with the setting value. If the illuminance is not equal to the set value, as LED driving current and duty cycle do not have direct proportion, it is necessary to change drive current through constant feedback and adjustment of PWM duty cycle so as to achieve the adjustment of illuminance. If illumination intensity is lower than the set value, PWM duty cycle is increased; if illumination intensity is higher than the set value, PWM duty cycle is reduced till the output value is equal to the set value or PWM reaches the upper and lower limits 20 and 100 , so that the illuminance remains the setting value, or supplemental lighting source is switche off. 


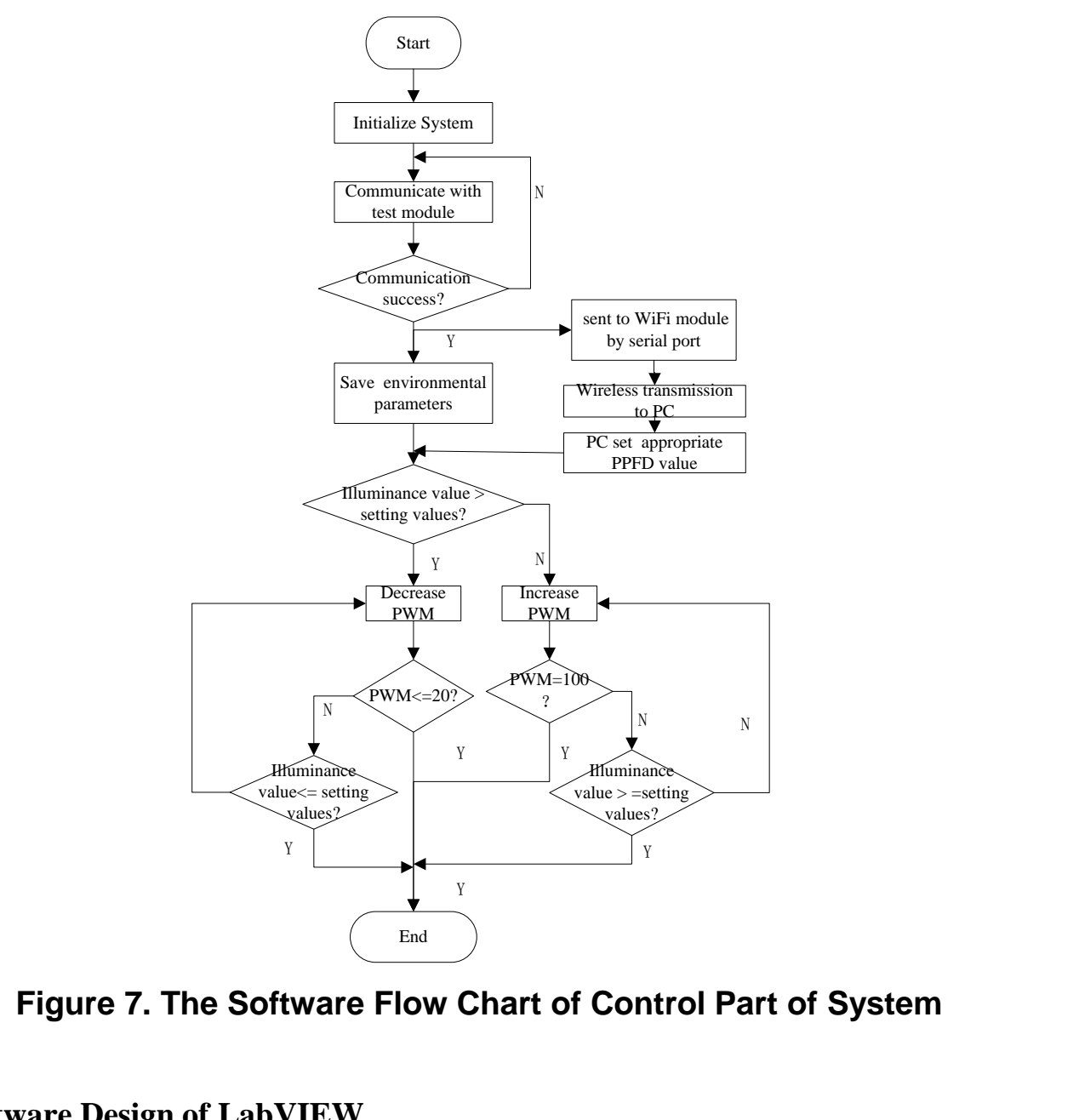

\subsection{Software Design of KabVIEW}

The system usesthe most represehtative graphical programming development platform LabVIEW in virtual instrument area as upper computer programming software. Microcomputer and LabVIEW achieve wireless communication through TCP/IP p otocol. The seryer-upper computer sends setting parameter data to the client-controlle and client-controller transmits illuminance and temperature \& humidity data to server. servepname and port in "TCP listening" leads to the input controls of IP address and port controls, delay millisecond is set to -1 . When the communication between the ser er and the client is established, we need to specify the IP address and port number. Port number is used to distinguish different communication services and manage multiple communication connection, the range of which is 0 to 65535 . Only if port number of client and server are the same, effective communication conduct.

LabVIEW program has two parts - front panel and program chart. The design of monitoring system mainly include user management module and function module. Among them, function module which is the main module consists of data acquisition and display, parameter setting and call, data storage function. User management interface verify user login information. Only if the user name and password are correct, user can enter the function module interface. As shown in Figure 8 , data acquisition and display interface of function module display the value and changing curve of PPFD of R, G , B intuitively. Value of temperature and humidity can also be observed in real time. Corresponding upper and lower limits of PPFD and temperature \& humidity can be set through click on the corresponding key or direct input. Indicator lights up if the threshold range is exceeded. As optical signal detected by illuminance sensor is expressed with 
illuminance, it is necessary to realize the transformation between illuminance intensity and PPFD through conversion relation (4).

The relation between PPFD and illuminance intensity $[8,19]$ is:

$$
U_{R}=\frac{\sum_{400}^{700} \lambda_{i} N_{i}(\lambda) \Delta \lambda}{81755.1 \sum_{\text {बRก }}^{780} V(\lambda) N_{i}(\lambda) \Delta \lambda} E_{R v}
$$

Where, $U_{R}$ refers to photon flux density, $E_{R v}$ refers to illumination intensity, $N_{i}(\lambda)$ refers to relative power density of spectrum and $V(\lambda)$ refers to human eye visualizing function.

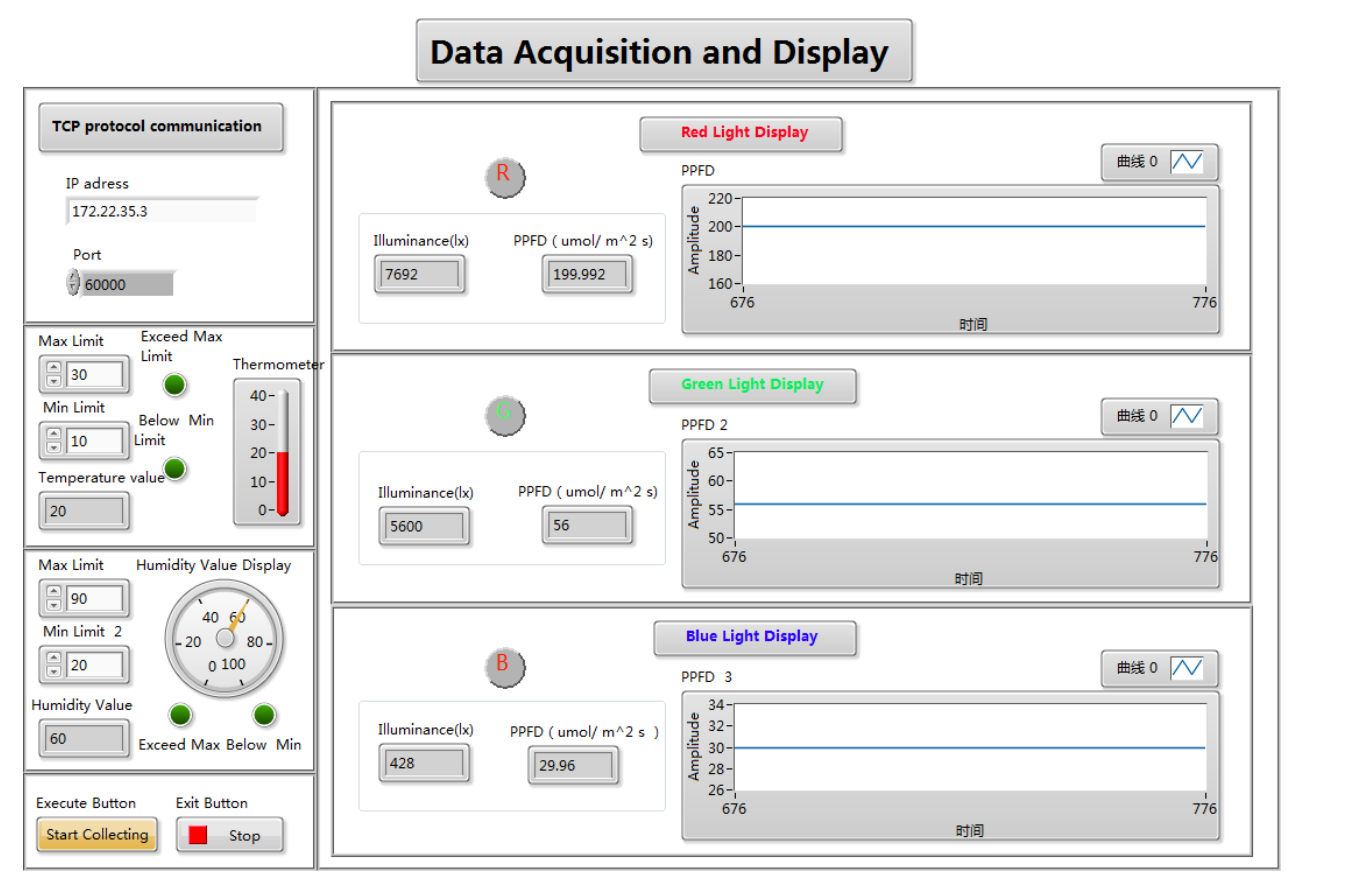

Figure 8. The Front Panel of LabVIEW Upper Computer

Parameters setting and call module implements expert database of plants illumination call, so that determines PPFD setting values of R, G, B light according to the reference, or you can choose to set PPFD value manually. The front panel of parameters call and setting is show in Figure 9. Data storage store the data including environment parameter values of temperature, humidity and PPFD of $\mathrm{R}, \mathrm{G}, \mathrm{B}$ light into PC, which is convenient for analysis of collected data and management of greenhouse system. 


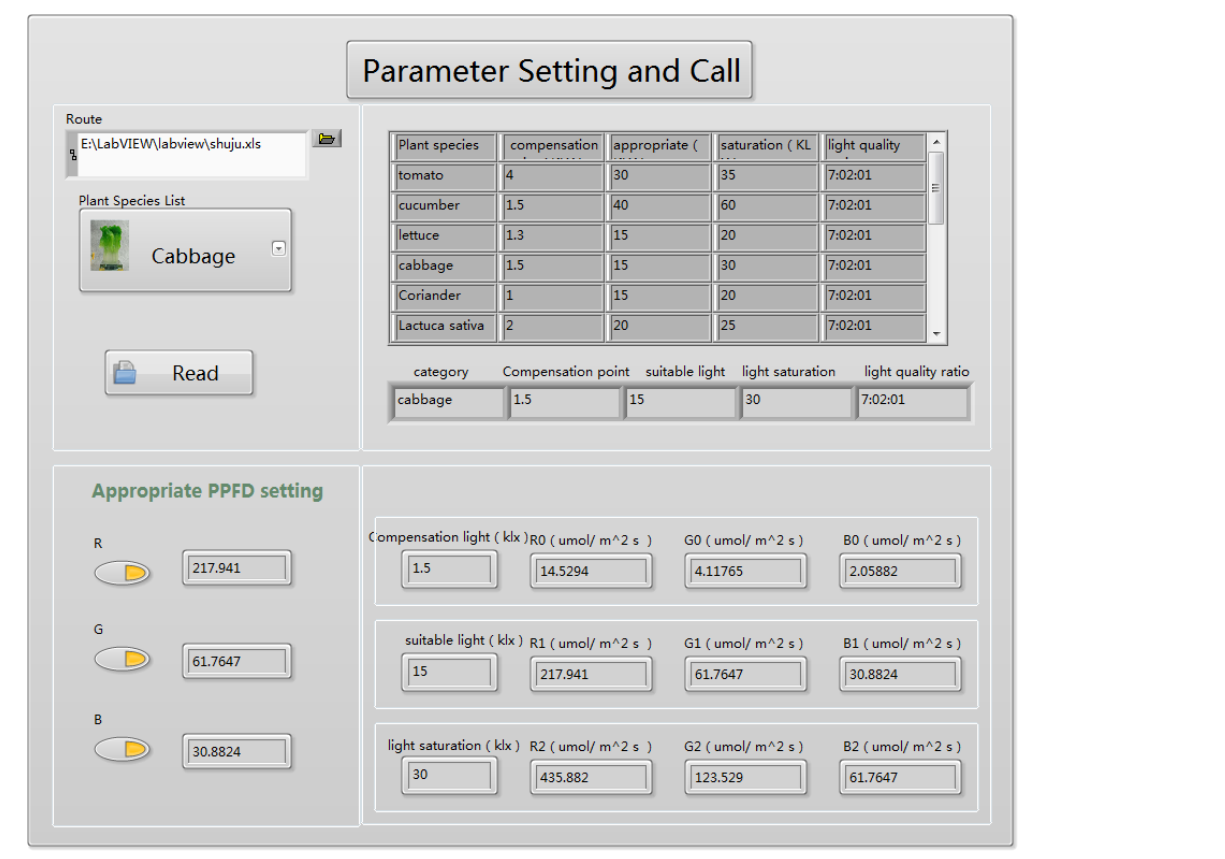

Figure 9. The Front Panel of Parameters Calland Setting

\section{System Test and Analysis}

This paper mainly tests and analyze the stability o LED supplemental lighting system. PPFD values of red, blue and green hights áre set as 200,30 and $56 \mu \mathrm{mol} \cdot \mathrm{m}^{-2} \cdot \mathrm{s}^{-1}$ respectively by upper computer i.e. Jight quality ratio is $\mathrm{R}: \mathrm{B}: \mathrm{G}=7: 1: 2$ [4]. The light area under LED light source unitmodule 20 cm with an irradiation area of $200^{2} \mathrm{~mm}^{2}$ is divided into 25 grid. PPFD values of the system at the center of 25 grid areas under different light environments are tested with LI-250A /luminometer. The result shows that adjustment of PWM signal of supplemental lighting system makes red, blue and green lights reach and maintain setting value when the sunshine is weak or there is no sunshine. Figure 10 shows the distribution of PPFD on the irradiation plane. The uniformity is calculated as $74 \%$ according to the ratio of maximum value to average value of PPFD. When sunshine is strong, PWM decreases to 0 and the supplemental lighting system stop to work as PPFD is far beyond setting value. At this time, sunlight is greenhouse light source. Above all, supplemental lighting yystem realize adaptive regulation and save energy consumption, which is of great application value for modern greenhouse supplemental lighting.

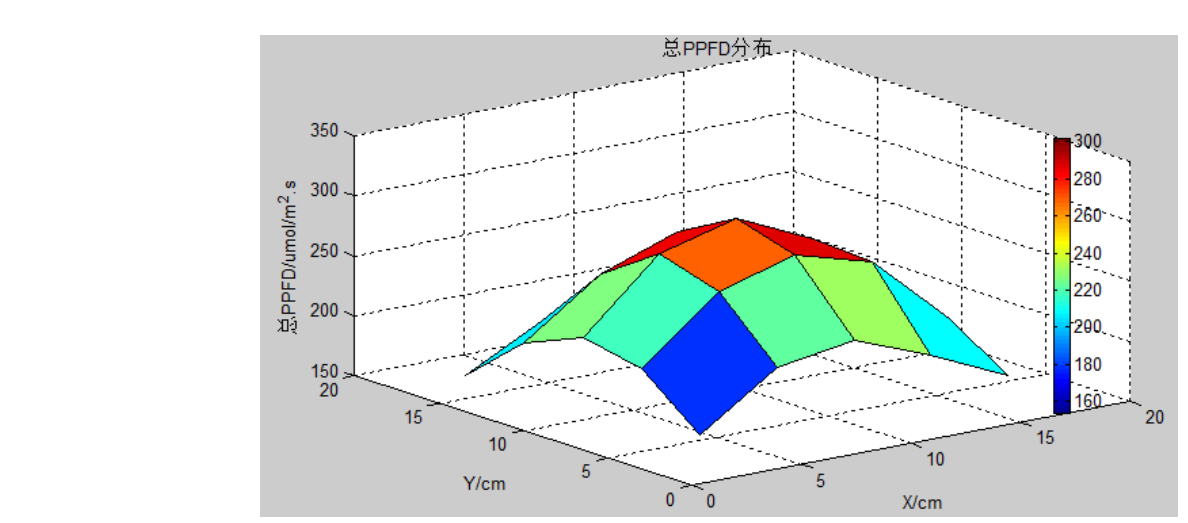

Figure 10. Distribution of PFD on Irradiation Plane 


\section{Conclusion}

This paper designs an intelligent supplemental lighting system which can conduct real-time monitoring based on the interface of LabVIEW upper computer, in which greenhouse environmental parameters can be set. Lower computer controller wirelessly communicate with LabVIEW through WiFi module. Lower computer collects and feeds back temperature, humidity and illuminance data in the environment. The light intensity of red, green and blue bands and light quality ratio exposure to plants meet needs of plants for lighting through the dynamic adjustment of PWM duty cycle. Meanwhile,the intelligent adjustment of temperature and humidity in the defined scope is achieved. Light source module is subject to simulation design using optical software TracePro. The test and analysis on the system shows uniform distribution of PPFD on irradiation plane, adaptive adjustment of setting PPFD value of R,G,B bands of light and small system error. Adaptive LED supplemental lighting system is appropriate for application of greenhouse supplementary lighting.

\section{Acknowledgments}

This work was supported by Performing Digital Integrated Key Technical Research, the National Science and Technology Support Plan of China(NO. 2014BAY03F01), and Digital LED Plant Growth Lighting Products with High Performance, movation Project of National Small and Medium-sized Enterprise in 2014(NO. 14226211200316).

\section{References}

[1] H. Zhang, "Effect of light environment control on the grouth and development in plant", Nanjing Agricultural University, (2010).

[2] Q.-C. Yang and Z.-G Xu, "Application Principle and Teehnology Progress in Using Light Emitting Diode (LED) Light Sources in Modern Agriculture", Journal of Agricultural Science and Technology, vol. 13,no. 5, (2011), pp.37 -43

[3] H.-H. Kiml and G. D. Goins, "Green-high Supplementation for Enhanced Lettuce Growth under Red-and Blue-light-emitting Diodes", HQRTSCIENCE, vol. 39, no. 7, (2004), pp. 1617-1622.

[4] I. Ilievaa and T. Ivanovaa, "Plant experinents with light-emitting diode module in Svet space greenhouse", Advances In Space Research, vol. 46,no. 7, (2010), pp. 840-845.

[5] A. Yano and K. Fujiwara, "Plant lighting system with five wavelength-band light-emitting diodes providing photon llux density and mixing ratio control", Plant Methods, vol. 8,no. 46, (2012).

[6] G. -Q. Zhou, Y.-Q. Xu and S. -H Fu, "Artificial light sources for production of greenhouse plants", Journal of Zhejiang Forestry College, vol. 25, no. 6, (2008), pp. 798-802.

[7] T. Liu, W. Liu and J. Ma, Distribution design method for LED plant light source with tunable ratio of red /blue photons", Transactions of the Chinese Society of Agricultural Engineering (Transactions of the CSAE), vol. 30, 10. (2014), pp. 154-159.

[8] X.-X. Tang Research and Design of LED Light Source for Plant Lighting", Tianjin Polytechnic University, (2014).

[9] G. -Q. Zhou, J. Zheng and Y.-M. Zhou, "Optimal design of LED assembled light source used in the prodaction of greenhouse plant", Journal of Optoelectronics Laser, vol. 19, no. 10, (2008), pp. $1320-1321$.

[10] Z. -X Su, "Design and Implementation of the Intelligent LED Plant Lighting Control System", Tianjin Polytechnic University, (2014).

[1V X. -Y Liu, Z. -G. Xu and L. Xue, "Design on LED Flexible light system and its effect on growth of spinach", Transactions of the CSAE, vol. 28, no. 1, (2012), pp. 1002-6819.

[12] X. -B. Li, "Real-time monitoring system of precision agriculture design and implementation based on LabVIEW", Zhengzhou University, (2013).

[13] Y. -K. Tang and S. -S. Guo, "Effects of Red and Blue Light Emitting Diodes (LED)on the Growth and Development of Lettuce", Space Medicine \&Medical Engineering, vol. 23,no. 3, (2010), pp. 206 212.

[14] Z. -M. Wang, F.-F. Song and Z. Xu, "Effect of Red and Blue LED Light Intensity on Growth and Quality of Lettuce", CHINA VEGETABLES, vol. 16, (2011), pp. 44-49.

[15] H. -L. Gao and D. Zhu, "The conversion of the units in the photometry for human eyes and plants", Journal of lamps and lighting, vol. 31,no. 2, (2007), pp. 34-36.

[16] H.-H. Zhang, Q. Yang and H. Jin, "Self-adaptive and precise supplementary lighting system for plant with controllable LED intensity”, Transactions of the CSAE, vol. 27, no. 9, (2011), pp. 153-158. 
[17] Y.-M. Zhou and G.-Q. Zhou, "A Design of Led Light System Used For Greenhouse Plants Based on MCU”, ACTA LASER BIOLOGY SINICA, vol. 22, no. 3, (2013), pp. 1007-7146.

[18] J. F. Boost, "Topology Dual-mode PWM LED Driver", Zhejiang University, (2007).

[19] A.-J. Mao and J. Wang, "Calculation and Application of Photosynthetic Photon Flux Density", Periodical Of Ocean Un Iversity Of China, vol. 36, (2006), pp. 151-155.

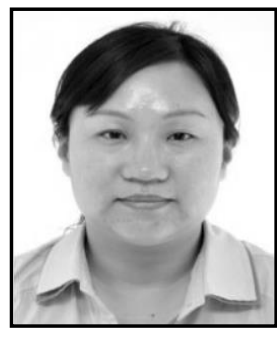

Pingjuan Niu, she obtained her bachelor and master of applied electronic technology and Semiconductor materials specialty at Hebei University of Technology in China in 1996 and 1999, respectively. She received $\mathrm{PhD}$ of micro- electronics and solid-state electronics professional at Tianjin University in China in 2002 ,on the research subjects of Semiconductor light-emitting devices, semiconductor lighting application system. From 2002 to the present she worked in Tianjin Polytechnic University, China. Now she is a professor and dean at School of Electrical Engineering and Automation, Tianjin Polytechnic University, Chma. Her current research interests include new semiconductor light emitting devices, LED driver circuit and semiconductor lighting application system research.

Yanyan Li, she is a postgraduate student of control engineering

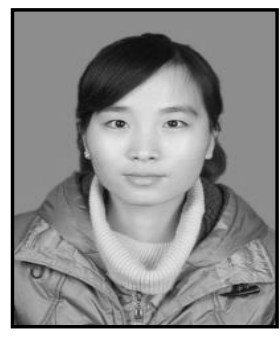
at Tianjin Polytechnjo University in China . Her current research interests include intelligent control of semiconductor lighting.
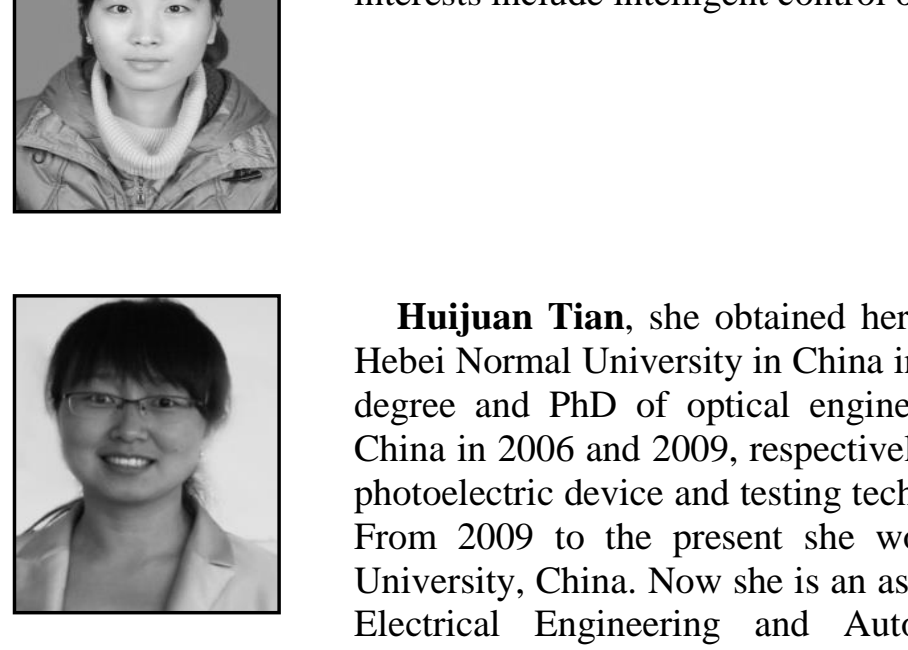

Huijuan Tian, she obtained her bachelor degree of Physics at Hebei Normal University in China in 2003, and received her master degree and $\mathrm{PhD}$ of optical engineering at Tianjin University in China in 2006 and 2009, respectively, on the research subjects of photpelectric device and testing technology, biomedical Photonics. From 2009 to the present she worked in Tianjin Polytechnic University, China. Now she is an associate professor at School of Electrical Engineering and Automation, Tianjin Polytechnic

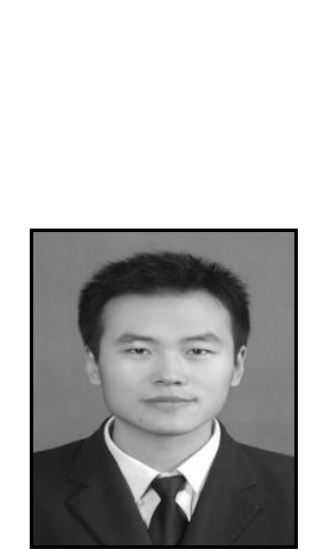
University, China. Her current research interests include semiconductor lighting application system integration technology, photoelectric device and testing technology and security and light detection .

Zhengxiao Su, he obtained his master degree of integrated circuit engineering at Tianjin Polytechnic University in China in 2015. His current research interests include semiconductor lighting intelligent control and integrated circuit control. 
International Journal of Hybrid Information Technology

Vol. 9, No.10 (2016)

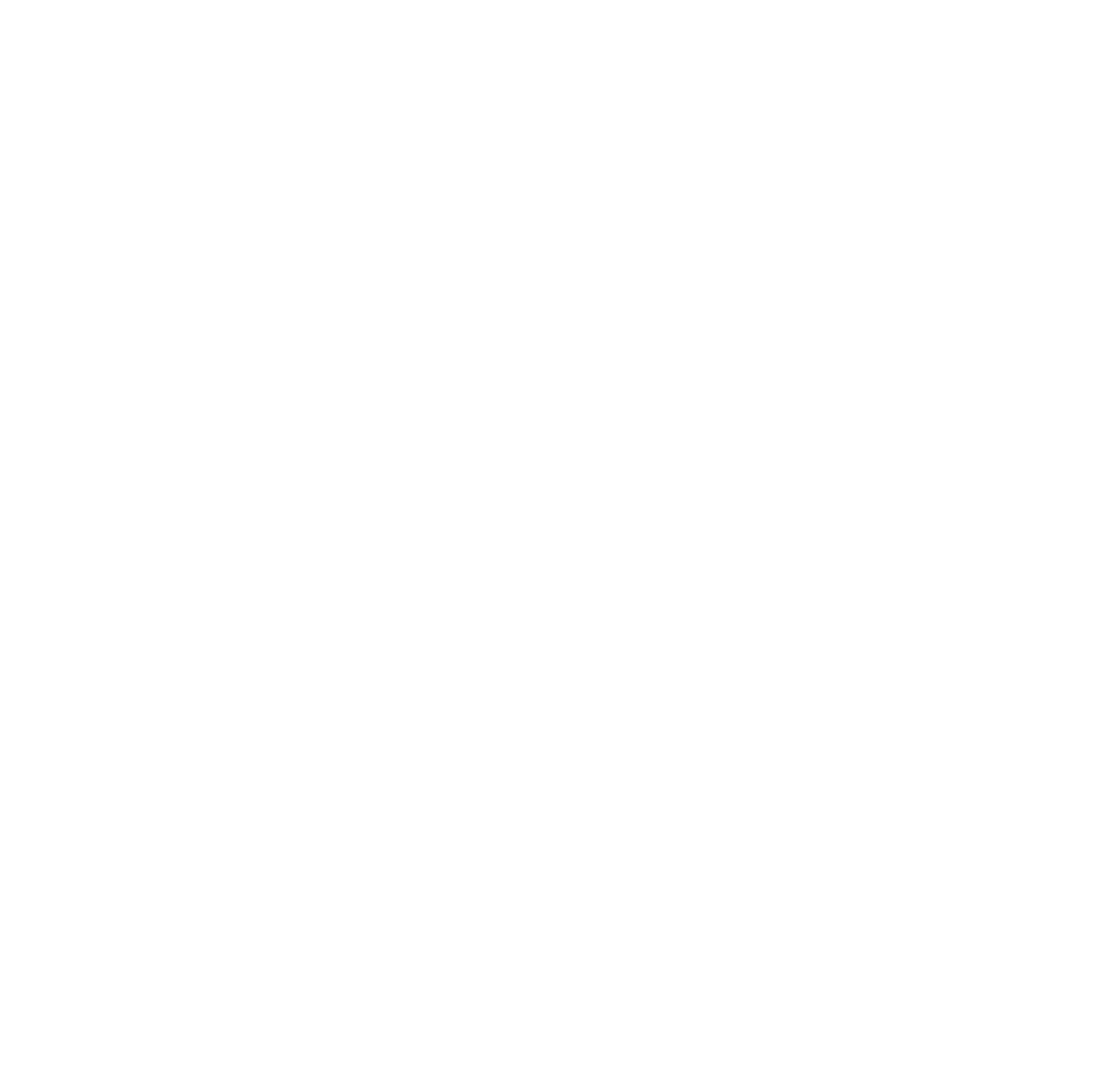

